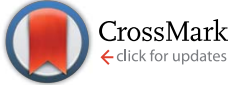

Cite this: J. Mater. Chem. B, 2014, 2 , 5898

Received 3rd April 2014

Accepted 10th July 2014

DOI: $10.1039 / c 4 t b 00522 h$

www.rsc.org/MaterialsB

\section{Enhancing mesenchymal stem cell response using uniaxially stretched poly( $\varepsilon$-caprolactone) film micropatterns for vascular tissue engineering application $\dagger$}

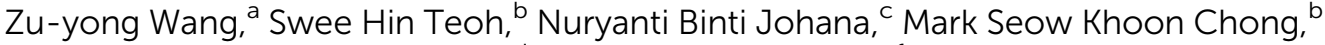 \\ Erin Yiling Teo, ${ }^{c}$ Ming-hui Hong, ${ }^{d}$ Jerry Kok Yen Chan ${ }^{\star c e f}$ and Eng San Thian*a
}

\begin{abstract}
Regeneration of tunica media with anisotropic architecture still remains a challenging issue for vascular tissue engineering (TE). Herein, we present the development of flexible poly( $\varepsilon$-caprolactone) (PCL) film micropatterns to regulate mesenchymal stem cells (MSCs) function for tunica media construction. Results showed that uniaxial thermal stretching of $\mathrm{PCL}$ films resulted in topographical micropatterns comprising of ridges/grooves, and improved mechanical properties, including yield stress, Young's modulus, and fracture stress without sacrificing film elasticity. Culturing on such PCL film micropatterns, MSCs self-aligned along the ridges with a more elongated morphology as compared to that of the unstretched film group. Moreover, MSCs obtained a contractile SMCs-like phenotype, with ordered organization of cellular stress filaments and upregulated expression of the contractile makers, including SM- $\alpha$-actin, calponin, and SM-MHC. The PCL film micropatterns could be rolled into a small-diameter 3D tubular scaffold with circumferential anisotropy of ridges/grooves, and in the incorporation of MSCs, which facilitated a hybrid sandwich-like vascular wall construction with ordered cell architecture similar to that of the tunica media. These results provide insights of how geometric cues are able to regulate stem cells with desired functions and have significant implications for the designing of a functionalized vascular TE scaffold with appropriate topographical geometries for guiding tunica media regeneration with microscale control of cell alignment and genetic expression.
\end{abstract}

\section{Introduction}

Cardiovascular diseases are the leading cause of death globally ( $\sim 38 \%$ and $\sim 50 \%$ of death in the U.S. and Europe, respectively). ${ }^{1,2}$ Tissue engineering (TE) could offer a novel therapy to improve or regenerate diseased vessels using a combination of biomaterials, cells, and engineering techniques. ${ }^{3}$ However, current vascular TE grafts remain limited by mismatched

${ }^{a}$ Department of Mechanical Engineering, National University of Singapore, 9 Engineering Drive 1, Singapore 117 576, Singapore. E-mail: mpetes@nus.edu.sg; Fax: +65 6779 1459; Tel: +65 65165233

${ }^{b}$ School of Chemical and Biomedical Engineering, Nanyang Technological University, Singapore

'Department of Reproductive Medicine, KK Women's and Children's Hospital, 100 Buikit Timah Road, Singapore 229899, Singapore. E-mail: jerrychan@nus.edu.sg; Fax: +65 6394 1618; Tel: +65 63941051

${ }^{d}$ Department of Electrical and Computer Engineering, National University of Singapore, Singapore

${ }^{e}$ Department of Obstetrics and Gynaecology, Yong Loo Lin School of Medicine, National University of Singapore, Singapore

${ }^{f}$ Cancer and Stem Cell Biology, Duke-NUS Graduate Medical School, Singapore

$\dagger$ Electronic supplementary information (ESI) available. See DOI: 10.1039/c4tb00522h compliance, thrombogenicity and/or inappropriate burst strength. ${ }^{2,4}$ A suitable scaffold for engineered, autologous and commercially available vascular grafts has yet to be developed.

In healthy blood vessels, the circumferentially aligned architecture of tunica media comprised of smooth muscle cells (SMCs) and elastin/collagen-enriched extracellular matrices (ECM) play important roles in maintaining the endothelium phenotype, mechanical strength and regulation of blood pressure., ${ }^{3,5}$ Geometric cues serving as artificial cell micro-environments could facilitate vascular TE scaffolds to replicate the complex architecture of tunica media. ${ }^{6-8}$ It has been known that geometric cues could trigger cell response via contact guidance., ${ }^{\mathbf{9 1 0}}$ Human SMCs cultured on micropatterned arrays organized into alignment as in native vessels ${ }^{7,11,12}$ and could obtain differentiation towards a contractile status. ${ }^{6,8}$ Despite these great advances in basic research, the incorporation of geometric cues into threedimensional (3D) tubular vascular TE scaffolds remains a challenging issue. Geometric features presently have often been fabricated on stiff and non-biodegradable substrates (e.g. Silicon $^{\mathbf{1 3}}$ and polydimethylsiloxane ${ }^{\mathbf{8}}$ ) that are not flexible and have little value for clinical translation. Although fabrication 
of biodegradable materials (e.g. poly( $\varepsilon$-caprolactone- $r$-L-lactide- $r$-glycolide $)^{6}$ and poly(L-lactide-co-e-caprolactone $)^{\mathbf{1 4}}$ ) could be realized by using electrospinning, soft-lithography and direct laser writing, these techniques often involve tedious procedures, unstable yield in a large area, and/or chemical solvent usage and residue. ${ }^{15}$ Such limitations related to the fabrication of geometric cues hindered the generation of commerically available, non-cytotoxic, and cost-effective vascular grafts.

Traditionally, isolated mature SMCs were utilized for tissueengineered vascular grafts (TEVGs), ${ }^{\mathbf{1 6}}$ but were found to dedifferentiate, overproliferate, and decrease the secretion of collagen/elastin in vitro. ${ }^{17-19}$ Recently, mesenchymal stem cells (MSCs) have shown great potential for vascular TE, ${ }^{17}$ and TEVGs constructed from MSCs can replicate an intact tunica media with histological and molecular phenotypes similar to that of the native vessels. ${ }^{18}$ Compared to the fully differentiated SMCs, MSCs were more easily obtained from the umbilical cord, bone marrow and adipose tissue, ${ }^{20}$ and they were more expandable in vitro up to millions of folds in culture, ${ }^{17}$ antithrombogenic, ${ }^{21}$ and immunocompatible due to the lack of expression of major histocompatibility complex II antigens. ${ }^{22}$ However, biochemical factors, such as transforming growth factor (TGF- $\beta 1$ ), plateletderived growth factor and ascorbic acid, were often required to differentiate MSCs for obtaining SMCs contractile phenotypes, which were considered to be costly and difficult in controlling the optimal concentration for effective stimulation. ${ }^{\mathbf{1 7 - 1 9 , 2 3}}$ Although geometric cues have been used to differentiate SMCs, they have not been reported on regulating MSCs towards SMClike contractile phenotypes.

Herein, we describe the development and application of flexible poly(e-caprolactone) (PCL) film micropatterns via a reproducible, simple, and solvent-free method of uniaxial thermal stretching. Vascular TE scaffolds based on the PCL film micropatterns could have sufficient theoretical burst strength and potential to promote stem cell response for tunica media regeneration.

\section{Materials and methods}

\subsection{Materials}

PCL $\left(M_{\mathrm{w}}=80000\right)$, phosphate buffer saline (PBS), penicillinstreptomycin (PS), fluorescein diacetate (FDA), TRITC-conjugated phalloidin, paraformaldehyde (PFA), triton-X 100, bovine serum albumin (BSA), and 4',6-diamidino-2-phenylindole (DAPI) were purchased from Sigma-Aldrich (Singapore). Monoclonal mouse anti-human smooth muscle $\alpha$-actin (SM- $\alpha$ actin), calponin, myosin heavy chain (SM-MHC), IgG2a, IgG1, IgG1-FITC, IgG1-RPE and IgG1-APC were purchased from Dako (Singapore). Monoclonal CD19 IgG1-RPE, CD 34 IgG1-RPE, CD45 IgG1-FITC, CD 73 IgG1-APC, and CD105 IgG1-RPE were purchased from Abcam (USA), and CD90 IgG1-FITC was purchased from Chemicon (USA). Goat anti-mouse IgG $(\mathrm{H}+\mathrm{L})$ FITC, Dulbecco's modified Eagle medium (DMEM), trypsinEDTA, and fetal bovine serum (FBS) were purchased from Life Technologies (USA). RNeasy Mini Kit and RT ${ }^{2}$ First Strand Kit were purchased from Qiagen (Singapore). Cell strainers, tissue culture plates (TCP) and flasks, and low-adhesion cell culture plates were purchased from BD Bioscience (USA), Thermo Fisher Scientific (USA), Nunc (Singapore), and Corning (Costar, Singapore), respectively.

\subsection{Fabrication of geometric cues on PCL films}

Geometric cues were fabricated on different PCL films. Briefly, solvent-cast PCL film (SC-PCL) was generated through casting PCL solution ( $2 \mathrm{wt} \%$ in dichloromethane) onto a glass mold and evaporating the solvent in a fume hood. ${ }^{24}$ Cast-stretch PCL film (CS-PCL) was obtained using an in-house developed machine via cast extrusion. ${ }^{25}$ Heat-press PCL film (HP-PCL) was generated through pressing PCL solid mass at $80{ }^{\circ} \mathrm{C}$ and $300 \mathrm{MPa} .{ }^{24}$ The PCL films were then cut into rectangular shapes $\left(5 \times 3 \mathrm{~cm}^{2}\right)$ and subjected to uniaxial stretching at a temperature of $54{ }^{\circ} \mathrm{C}$ and a draw ratio of 4 (Fig. 1a) for generating microstructured topographies as previously described. ${ }^{15}$ For convenience, the stretched PCL films were named as $\mathrm{UX}_{\mathrm{SC}}-\mathrm{PCL}, \mathrm{UX}_{\mathrm{CS}}-\mathrm{PCL}$ and $\mathrm{UX}_{\mathrm{HP}}$-PCL. There were no obvious changes in $M_{\mathrm{w}}$ and $M_{\mathrm{n}}$ for PCL films before and after uniaixal stretching. For cell studies, PCL films were surface-modified using alkaline hydrolysis (3 mol L ${ }^{-1} \mathrm{NaOH}$ solution) as previously described, at room temperature for 24 hours to obtain a water contact angle of $\sim 52^{\circ}$ for facilitating cell adhesion. ${ }^{15,26}$

\subsection{Morphological characterization}

The microstructured topographies of PCL films were characterized using field-emission scanning electron microscopy (FE-SEM; S-4300, Hitachi, Japan). Samples were sputter-coated with gold at $10 \mathrm{~mA}$ for $30 \mathrm{~s}$, and images were taken under different magnifications at a voltage of $15 \mathrm{kV}$. The PCL film morphologies were further confirmed using atomic force microscopy (AFM; MFP-3D, Asylum Research, USA) via a tapping scan over an area of $30 \times 30 \mu \mathrm{m}^{2}$. Inter-ridge distance was measured from SEM images by drawing lines perpendicular to the stretch direction and presented as a length of the line divided by the crossed ridge number. Ridge depth was analyzed from AFM images with topographical profiles obtained along lines perpendicular to the ridges using the built-in function of Igor Pro6 (USA). Three samples were used for each kind of PCL film, and results were averaged as the mean.

\subsection{Measurement of mechanical properties}

The mechanical properties of PCL films were measured using a tensile testing machine (Model 3345, Instron, USA). ${ }^{26}$ Samples were prepared into strips of $5 \times 30 \mathrm{~mm}^{2}$ with a major edge along the stretching direction. The thickness of each sample was measured using a digimatic micrometer (APB-1D, Mitutoyo Corporation, Japan) at five random positions. Testing was performed using a load cell of $100 \mathrm{~N}$ at a pulling rate of $10 \mathrm{~mm}$ $\min ^{-1}$. An offset-strain of 0.005 was used for the stretched film samples to determine their yield stress and strain, and for unstretched film samples, a low yield point was used to determine the yield stress and strain at the linear-elastic region. Theoretical burst strength was calculated based on Laplace's law 
(a)

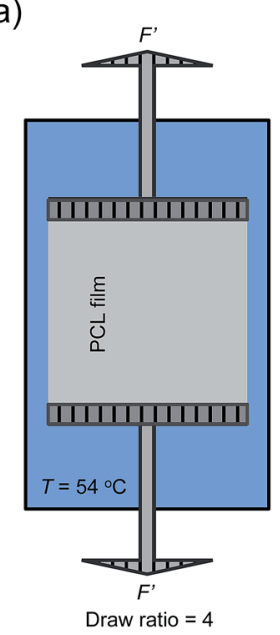

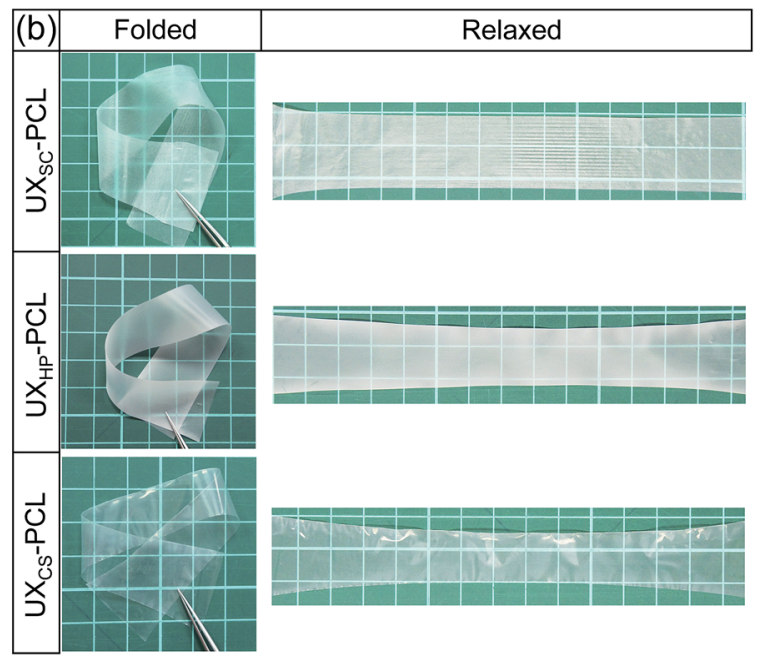

Fig. 1 (a) Schematic illustration of the fabrication set-up for uniaxial thermal stretching of $P C L$ films $\left(T=54{ }^{\circ} \mathrm{C}\right.$; draw ratio $\left.=4\right)$. (b) Uniaxially stretched flexible PCL films experiencing the bending and folding, and recovering to their original status. $U X_{S C}-P C L, U X_{H P}-P C L$ and $U X_{C S}-P C L$ representing the stretched films with a pre-fabrication of solvent cast (SC), heat press (HP) and cast stretch (CS), respectively.

(burst strength $=$ materials yield stress $\times$ thickness/radius). ${ }^{27}$ For each kind of PCL film, three sample copies were tested.

\subsection{In vitro cellular isolation and culture}

Human tissue collection for research purposes was approved by the Domain Specific Review Board of National Healthcare Group, in compliance with international guidelines regarding the use of fetal tissues for research. ${ }^{28}$ In all cases, patients gave separate written consent for the use of their collected tissues.

MSCs were isolated from human fetal bone marrow. Through flushing the marrow cells out of femurs and passing a cell strainer $(40 \mu \mathrm{m})$, single-cell suspension was obtained. Cells were then seeded in a tissue culture flask $(75 \mathrm{ml})$ at $10^{6}$ per $\mathrm{cm}^{2}$ and cultured in D10 medium (DMEM $+10 \% \mathrm{FBS}+1 \% \mathrm{PS}$ ) for three days. Non-adherent cells were removed by changing the medium. The adherent cells (MSCs) were further cultured and recovered from the primary culture after one week. As previously described, the obtained cells were checked for standard stem cell markers through immunochemistry analysis using flow cytometry (FACS, Beckman, USA; Table S1†)..$^{28,29}$

\subsection{Characterization of MSCs organization and morphologies}

The organization and morphologies of MSCs were characterized through cytoplasmic staining. ${ }^{15}$ MSCs seeded on substrate samples (unstretched and uniaxially stretched PCL films) were cultured for a pre-determined period to maintain a subconfluence towards single-cell analysis. After washing with PBS, cells were incubated with FDA $\left(5 \mu \mathrm{g} \mathrm{L}^{-1}\right)$ at room temperature for $10 \mathrm{~min}$, and after washing thrice, they were immediately visualized using confocal laser scanning microscopy (CLSM, FV1000, Olympus, Japan). Images were analyzed using the builtin function of NIH ImageJ software (USA). All cells in contact with other cells and image edges were manually removed from the data sets. The cell angle was determined using the orientation of the major elliptic axis of the individual cell. A preferential cell orientation has been determined and set as $0^{\circ}$. All cell angles were then normalized to the preferential cell orientation. Cell number within each degree from $-90^{\circ}$ to $+89^{\circ}$ was calculated and normalized such that the total sum was unity. A perfectly isotropic sample would be expected to have an even distribution of cell angles in each degree (a value $=1 / 180$ $\times 100 \%$ ). Cells with angles falling into $\pm 10^{\circ}$ were considered to be aligned..$^{15}$ The isotropic sample would have $\sim 11.7 \%$ of cells in $\pm 10^{\circ}$ (total $21^{\circ}$, a value $=21 \times 1 / 180 \times 100 \%$ ). Values above $11.7 \%$ indicated increased alignment. Cell elongation was described as a long-to-short elliptic axis index (a ratio of the major and minor elliptic axes). Three samples were used for each PCL film group, and CLSM images were taken at four random regions of each sample for data analysis.

\subsection{Characterization of MSCs cytoskeleton and nucleus organization and morphologies}

The organization and morphologies of MSCs subcellular organelles were characterized through F-actin and DNA staining. After culturing for a pre-determined period, MSCs were fixed (3.7\% PFA in PBS), permeabilized (0.1\% Triton-X 100 in PBS) and blocked ( $2 \%$ BSA in PBS). The cells were sequentially incubated with TRITC-conjugated phalloidin $(1: 200$ in PBS) and DAPI (1:1000 in PBS) for F-actin and DNA labeling, respectively. CLSM images were analyzed using the built-in function of NIH ImageJ software. Cell nuclei with angles falling into $\pm 10^{\circ}$ were considered to be aligned. A perfectly isotropic sample would be expected to have an alignment efficiency of $\sim 11.7 \%$. Nucleus elongation was described using a cell nucleus shape index (CNSI, circularity $=4 \times \pi \times$ area/perimeter ${ }^{2}$ ), with a CNSI of 1 representing a circle. Three samples were used for each PCL film group, and CLSM images were taken at four random regions of each sample for data analysis. 


\subsection{Quantitative reverse transcription polymerase chain reaction (qRT-PCR)}

The expression of gene targets (Table S2 $\dagger$ ) in MSCs was investigated using real-time qRT-PCR. ACTA2, CNN1 and MYH11 were the targeted gene sequences of SM- $\alpha$-actin, calponin, and SM-MHC, respectively, and related to human vascular SMCs early-, middle- and late-term differentiation, respectively. ${ }^{\mathbf{8 , 1 9 , 3 0 , 3 1}}$ MSCs seeded on TCP and PCL film samples were cultured for five days in a D10 medium. Total RNA was extracted using RNeasy Mini Kit, and cDNA was synthesized using $\mathrm{RT}^{2}$ First Strand Kit. qRT-PCR was performed on an ABI Prism 7000 realtime detection system (AB Applied Biosystem, USA) for 45 cycles. Primers specific to the targeted genes were obtained from PrimerBank (http://pga.mgh.harvard.edu/primerbank/). The relative expression levels of each gene targeted were determined by comparing the quantified cDNA transcript levels to that of glyceraldehyde-3-phosphate dehydrogenase (GAPDH, used as the internal standard). ${ }^{15}$ The results were finally normalized to the relative expression levels of each gene of the TCP group. Three experimental samples were used for each testing group, and detection was performed in triplicates of each sample for data analysis.

\subsection{Immunocytochemistry assays}

The protein expression of SMCs contractile markers in MSCs was analyzed through qualitative and quantitative immunocytochemistry assays. MSCs seeded on PCL film samples were cultured for five days under identical conditions in a D10 medium.

Intracellular qualitative analysis. After culturing, MSCs were fixed, permeabilized, and blocked. MSCs were then incubated with the primary monoclonal antibodies specific-targeted to SMCs contractile markers or the related IgG isotypes as negative control (Neg Ctrl) at room temperature for $60 \mathrm{~min}$ (Table S3 $\dagger$ ). After washing thrice with PBS, cells were further incubated with the fluorescence-labeled second antibody (goat anti-mouse IgGFITC) at room temperature for another $60 \mathrm{~min}$. After washing thrice with PBS, cells were finally incubated with DAPI $(1: 1000$ in PBS) for 5 min for nucleus visualization. Cell images of each SMCs contractile marker were captured by CLSM using identical parameters for all groups.

Intracellular quantitative analysis. After culturing, MSCs were treated with trypsin-EDTA $(0.25 \%)$ and collected through centrifugation (400 rcf, $5 \mathrm{~min}$ ). Cells after fixation, permeabilization and blocking were immunolabeled with the primary monoclonal antibodies or the related IgG isotypes (Neg Ctrl), followed by the incubation of the fluorescence-labeled second antibody. Human perivascular SMCs isolated from the arteries of umbilical cord (UCPVCs) were used as a positive control as previously described. ${ }^{19}$ The intracellular fluorescence of 10000 cells of each sample was detected using a FACS equipped with an argon laser emission of $488 \mathrm{~nm}$. A gate was set to ensure that a positive cell number in Neg Ctrl was less than $0.5 \%$. Data were analyzed using the built-in function of Summit V4.3.02 software (Beckman, USA). Three experimental samples were used for each testing group, and detection was performed in triplicates of each sample for data analysis.

\subsection{Statistical analysis}

Data analysis was performed on Prism 5 Software. Results were reported as mean $\pm \mathrm{SD}$. A value of $p<0.05$ was considered to be statistically significant.

\section{Results and discussion}

\subsection{Fabrication of $3 D$ self-assembling micropatterns on flexible PCL films}

The development of a suitable scaffold is crucial for vascular TE to achieve engineered, autologous and commercially available grafts. Herein, we present the development of a readily engineered, flexible and light-weight film with micropatterned geometries for functionalized vascular TE scaffold construction. Fig. 1a illustrates the designed set-up for uniaxial thermal stretching of PCL films. As shown in Fig. 1b, the uniaxially stretched PCL films were flexible enough to allow bending and folding, and readily recover to their original states. SEM images show that the uniaxially stretched PCL films obtained micropatterned topographies comprised of highly orientated ridges and grooves along the stretching direction, although different morphologies were observed for the unstretched PCL films (Fig. 2a and b). AFM examination confirmed the microstructured surfaces on uniaxially stretched PCL films (Fig. 2b). Comparatively, the AFM image of $\mathrm{UX}_{\mathrm{CS}}-\mathrm{PCL}$ reveals additional fibrous structures in nanoscale. Such filaments also existed on the ridges of $\mathrm{UX}_{\mathrm{SC}}-\mathrm{PCL}$ and $\mathrm{UX}_{\mathrm{HP}}-\mathrm{PCL}$ based on the observations at a high magnification of SEM (e.g. a magnification of x25 000, data not shown). These observations suggested that uniaxial stretching as a newly developed method for surface micropatterning could be compatible with current film fabrication techniques such as solvent cast and heat press.

Quantitative analyses of the SEM and AFM images showed that among the stretched PCL films, $\mathrm{UX}_{\mathrm{SC}}-\mathrm{PCL}$ had the widest inter-ridge distance ( $v s$. $\mathrm{UX}_{\mathrm{HP}}-\mathrm{PCL}$ and $\mathrm{UX}_{\mathrm{CS}}$-PCL: $9.0-10.2 \times, p<$ 0.001; Fig. 2c) and the deepest ridge depth (vs. $\mathrm{UX}_{\mathrm{HP}}-\mathrm{PCL}$ and $\mathrm{UX}_{\mathrm{CS}}-\mathrm{PCL}: 2.9-17.5 \times, p<0.001$; Fig. $2 \mathrm{~d}$ ). $\mathrm{UX}_{\mathrm{HP}}-\mathrm{PCL}$ as compared to $\mathrm{UX}_{\mathrm{CS}}-\mathrm{PCL}$ revealed a considerable increase in ridge depth $(5.1 \times$ increase, $p<0.001)$, although they shared an approximate inter-ridge distance of $\sim 5 \mu \mathrm{m}(p>0.05)$. These results suggested that the pre-fabrication of PCL films could have an effect on the formation of uniaxial stretching-induced micropatterns. It should be noted that uniaxial stretching under different conditions could also result in ridges/grooves with different sizes. ${ }^{15}$ With a decrease in stretching temperature $\left(54 \rightarrow 21^{\circ} \mathrm{C}\right)$ and draw ratio $(4 \rightarrow 2)$, the ridge length reduced and inter-ridge distance increased. Such discontinuous ridges with smaller ridge lengths and wider grooves could facilitate cell-cell contacts to interfere with cell-substrate interaction, and lead to the delayed and reduced cell alignment. ${ }^{32-34}$ Therefore, in this study, uniaxial stretching of the PCL films was performed at an elevated temperature of $54{ }^{\circ} \mathrm{C}$ and a draw ratio of 4 . Higher temperatures and draw ratios were not chosen, because the PCL melting point is $\sim 60{ }^{\circ} \mathrm{C},{ }^{15}$ and under these conditions, PCL films were easily broken. Previously, we proposed that the surface micro-ridges of uniaxially stretched PCL film were 

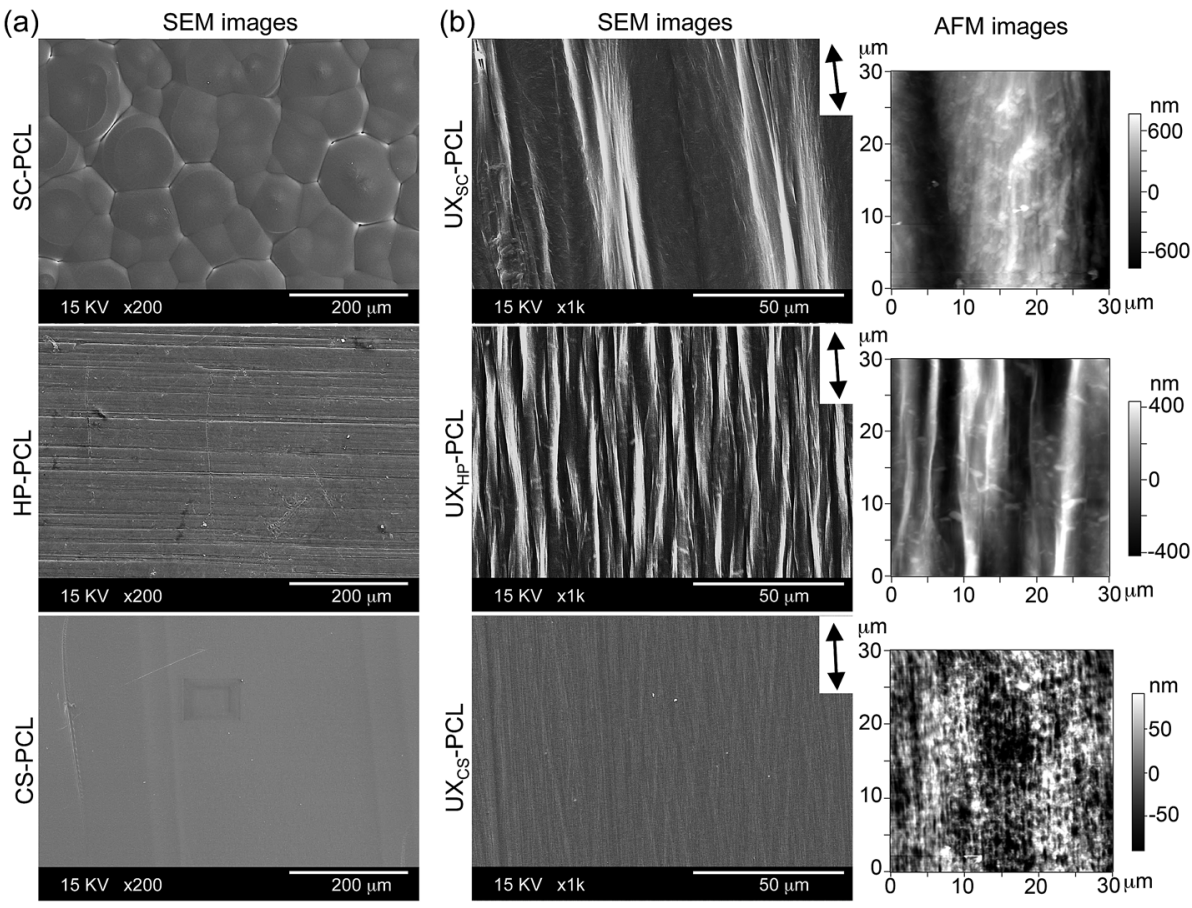

(c)

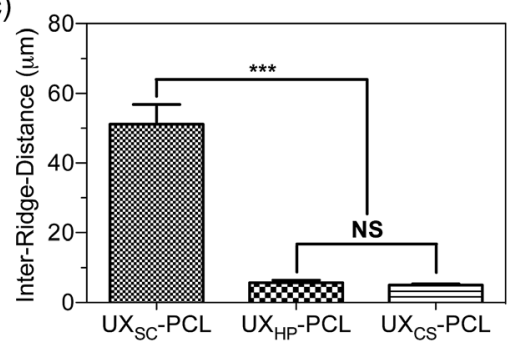

(d)

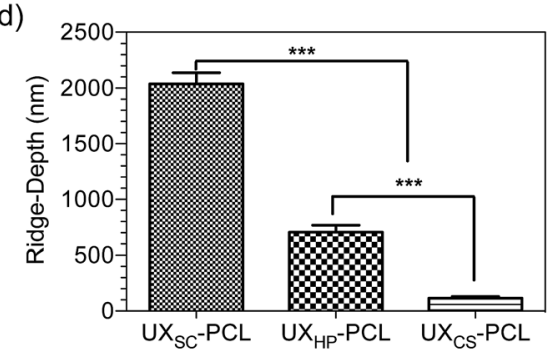

Fig. 2 Micropatterned 3D topographies of the uniaxially stretched PCL films. (a) SEM images of the un-stretched PCL films. (b) SEM and AFM images of the uniaxially stretched PCL films that revealed a micropatterned morphology comprised of orientated ridge/groove geometries (double-headed arrow: stretching direction). (c and d) Quantitative analyses of the inter-ridge distance and ridge depth. ( $n=3 ; * * *, p<0.001 ;$ NS, $p>0.05)$.

generated from recrystallized PCL crystals. ${ }^{15}$ During the fabrication processes, PCL molecular chains were orientated because of stretching and formed into ordered, multi-layered lamellas to self-assemble into new crystals following the direction of the stretching. ${ }^{35}$ Because the crystals were more rigid than the amorphous structures, they would have less deformation under uniaxial stretching, whereas the amorphous regions became thinner and formed into grooves to reveal the crystals from the film surface as ridges..$^{15}$ In this study, the observed different sizes of the ridges/grooves on three uniaxially stretched PCL films were in agreement with the previously proposed mechanism, as film-processing history has been known to affect polymeric crystallization. ${ }^{36}$

For potential application for vascular TE, we then investigated the mechanical properties of PCL films. As shown in Fig. 3a, tensile stress-strain curves showed elastic deformation up to the proportional limit for $\mathrm{UX}_{\mathrm{SC}}-\mathrm{PCL}, \mathrm{UX}_{\mathrm{CS}}-\mathrm{PCL}$ and $\mathrm{UX}_{\mathrm{HP}^{-}}$ PCL, followed by plastic deformation characterizing with considerable strain increase but non-corresponding rise in the loading stress. Quantitatively, $\mathrm{UX}_{\mathrm{HP}}-\mathrm{PCL}$ as compared to
$\mathrm{UX}_{\mathrm{SC}}-\mathrm{PCL}$ and $\mathrm{UX}_{\mathrm{CS}}-\mathrm{PCL}$ exhibited higher yield stress $(1.3-1.5 \times$, $p<0.05$; Table 1), increased Young's modulus (3.1-3.6×, $p<$ $0.001)$, and higher fracture stress $(1.8-3.4 \times, p<0.001)$ and strain $(1.3-1.5 \times, p<0.001)$. The yield strain of $\mathrm{UX}_{\mathrm{HP}}-\mathrm{PCL}$ was comparable with that of $\mathrm{UX}_{\mathrm{CS}} \mathrm{PCL}(p>0.05)$ and larger than that of $\mathrm{UX}_{\mathrm{SC}}-\mathrm{PCL}(0.9 \times$ increase, $p<0.001)$. Comparing $\mathrm{UX}_{\mathrm{HP}}-\mathrm{PCL}$ and HP-PCL, it was found that uniaxial stretching transformed the film's stress-strain curve, and the latter experienced a reduced stress after achieving the proportional limit (Fig. 3b). Uniaxial stretching conferred $\mathrm{UX}_{\mathrm{HP}}-\mathrm{PCL}$ with a significant increase in yield stress $(2.5 \times$ increase, $p<0.001$; Table 1$)$, Young's modulus $(2.1 \times$ increase, $p<0.001)$ and ultimate stress $(2.6 \times$ increase, $p<0.001)$ without sacrificing the film's elasticity $(p>0.05)$. Moreover, the film thickness of $\mathrm{UX}_{\mathrm{HP}}$-PCL was reduced $(0.2 \times$ of HP-PCL, $p<0.001)$, resulting in a low weightto-surface ratio of $\sim 5 \mathrm{mg} \mathrm{cm}^{-2}$.

Previously, micropatterned ridges/grooves have shown robust regulation on vascular cell behavior. ${ }^{6,8}$ However, their application for functionalizing vascular TE scaffolds remained limited in research, ${ }^{12,37}$ as current fabrication techniques, such 
(a)

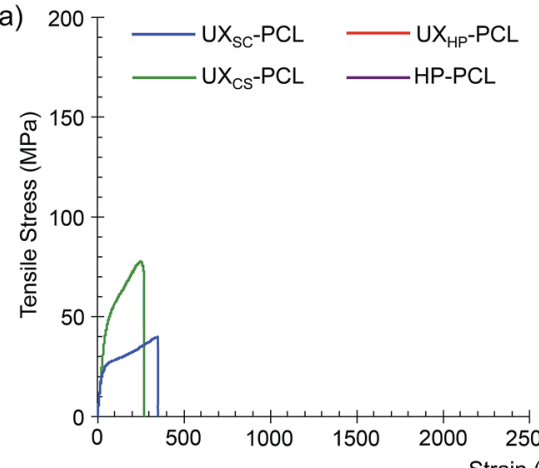

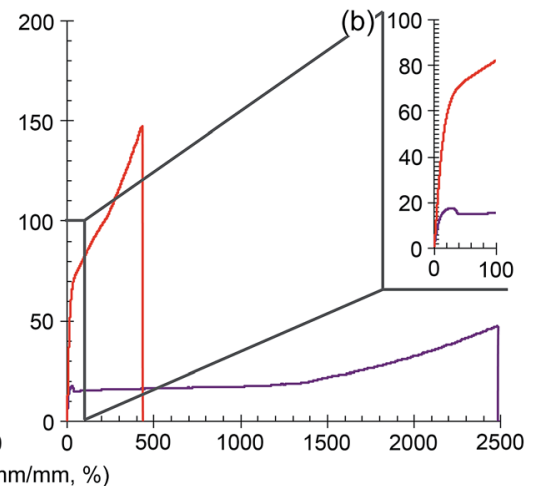

Fig. 3 Tensile test of the PCL film mechanical properties. (a) Representative stress-strain curves of $U X_{S C}-P C L, U X_{C S}-P C L, U X_{H P}-P C L$ and $H P-$ PCL. (b) The enlarged portion of UX $\mathrm{X}_{\mathrm{HP}}-\mathrm{PCL}$ and HP-PCL stress-strain curves.

Table 1 Film tensile properties and theoretical burst strength $(n=3)$

\begin{tabular}{|c|c|c|c|c|c|c|c|}
\hline PCL film & $\begin{array}{l}\text { Thickness } \\
(\mu \mathrm{m})\end{array}$ & $\begin{array}{l}\text { Yield stress } \\
\text { (MPa) }\end{array}$ & $\begin{array}{l}\text { Yield strain } \\
(\%)\end{array}$ & $\begin{array}{l}\text { Young's modulus } \\
\text { (MPa) }\end{array}$ & $\begin{array}{l}\text { Ultimate stress } \\
\text { (MPa) }\end{array}$ & $\begin{array}{l}\text { Ultimate strain } \\
(\%)\end{array}$ & $\begin{array}{l}\text { Burst strength } \\
\text { (mm Hg) }\end{array}$ \\
\hline $\mathrm{UX}_{\mathrm{CS}}-\mathrm{PCL}$ & $16.3 \pm 1.6$ & $42.8 \pm 8.1$ & $35.8 \pm 4.3$ & $107.3 \pm 23.4$ & $81.0 \pm 4.2$ & $277.5 \pm 10.6$ & $4544.9 \pm 864.5$ \\
\hline $\mathrm{UX}_{\mathrm{HP}}-\mathrm{PCL}$ & $37.9 \pm 5.5$ & $55.7 \pm 7.2$ & $31.3 \pm 2.8$ & $336.8 \pm 34.9$ & $145.9 \pm 15.0$ & $419.3 \pm 15.0$ & $11556.3 \pm 1355.8$ \\
\hline HP-PCL & $169.7 \pm 17.1$ & $16.0 \pm 3.0$ & $30.7 \pm 2.8$ & $109.2 \pm 33.2$ & $40.9 \pm 9.8$ & $2450.0 \pm 0.0$ & - \\
\hline
\end{tabular}

${ }^{a}$ Tubular vascular scaffolds engineered with a single film layer at an approximate diameter of $2.3 \mathrm{~mm}$.

as soft-lithography and direct laser writing, were often applied on stiff and/or thick substrates, and involved tedious procedures and usage of various solvents. ${ }^{\mathbf{1 4 , 1 5 , 3 8}}$ Comparatively, our study realized micropatterns on a flexible and light-weight PCL film via uniaxial stretching. This development imparted the microstructures with flexible film properties to facilitate rolling into vascular TE scaffolds and also enabled solvent-free and reproducible topographical geometries with simple procedures. Previously, although electrospinning was considered as an established strategy that could realize the specific circumferential alignment of native arteries, it has not yet generated a vascular graft with sufficient burst strength from biological materials alone..$^{37,39}$ Interestingly, the present method of uniaxial stretching, in addition to surface structuring, has also enhanced film substrates with improved mechanical performances. Based on Laplace's law, the theoretical burst strength of $\mathrm{UX}_{\mathrm{HP}}$-PCL-based vascular TE scaffolds at a diameter of 2.3$4.6 \mathrm{~mm}$ could be $>5000 \mathrm{~mm} \mathrm{Hg}$, which was higher than those of scaffolds based on $\mathrm{UX}_{\mathrm{SC}}-\mathrm{PCL}$ and $\mathrm{UX}_{\mathrm{CS}}$-PCL (1.5-3.7 $\times$ increase, $p<0.001$; Table 1), and is sufficient to withstand the normal inside pulsatile pressure of the human mammary artery. ${ }^{27}$

\subsection{Flexible PCL film micropatterns to align MSCs organization}

We further investigated the biological functions of uniaxially stretched PCL films. The in vitro isolated and expanded MSCs grew as plastic-adherent cells and revealed a typical stem cell immunophenotype (Table $\mathrm{S} 1 \dagger)$, which was negative $(<1.5 \%)$ for the haemopoietic and endothelial markers: CD19, CD45 and CD34, and positive (>95\%) for the mesenchymal markers: CD73 (SH-3, SH-4) and CD105 (SH-2) and cell adhesion molecules: CD90. Culturing MSCs on PCL films, CLSM images of live-cell cytoplasmic staining showed the ordered cell organization on $\mathrm{UX}_{\mathrm{SC}}-\mathrm{PCL}$ and $\mathrm{UX}_{\mathrm{HP}}-\mathrm{PCL}$ in a direction along the ridges (Fig. 4a). Cellular orientation and morphological analysis showed that MSCs cultured on $\mathrm{UX}_{\mathrm{SC}}-\mathrm{PCL}$ and $\mathrm{UX}_{\mathrm{HP}}-\mathrm{PCL}$ achieved a significant increase in alignment $(2.7 \times$ increase, $p<0.001$; Fig. $4 \mathrm{~b})$ and elongation $(0.5 \times$ increase, $p<0.001)$ efficiencies as compared to those of the un-stretched PCL film groups, suggesting that the cells obtained a capability of self-ordering into the aligned organization as observed in the tunica media. ${ }^{3}$ In contrast, MSCs grew on $\mathrm{UX}_{\mathrm{CS}}$-PCL and the un-stretched PCL films in a random fashion. It should be noted that MSCs grown on CS-PCL exhibited more localized cell alignment than those of the cells on SC-PCL and HPPCL. This could be attributed to the higher number of cells obtained on SC-PCL, as MSCs with in vitro culture approaching confluence have been known to self-organize into orientation within a small area. ${ }^{15}$ However, this localized alignment was inconsistent in the cell orientation (Fig. 4a) and has not resulted in CS-PCL with better cell alignment efficiency as compared to others (Fig. 4b). It should also be noted that compared to CS-PCL, $\mathrm{UX}_{\mathrm{CS}}$-PCL did not impart MSCs with an increase in alignment efficiency $(p>0.05)$, although more elongated cell morphologies were observed. Among the three uniaxially stretched PCL films, $\mathrm{UX}_{\mathrm{HP}}$-PCL elicited ordered MSCs growth with the highest alignment $(1.3-3.9 \times, p<0.001)$ and elongation $(1.1-1.4 \times, p<0.01)$ efficiencies. 

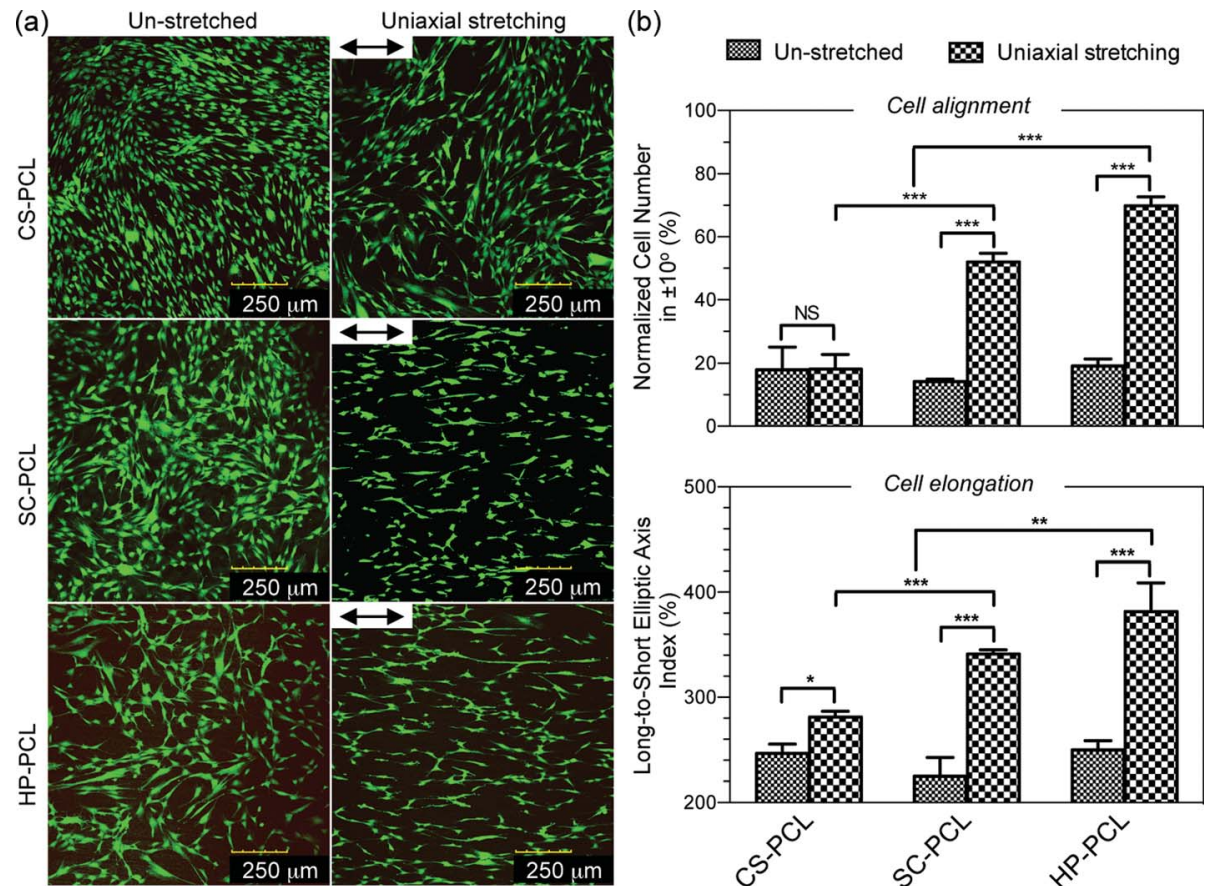

Fig. 4 Aligned organization of mesenchymal stem cells (MSCs). Cells (passage 3, $5 \mathrm{k} \mathrm{cm}^{-2}$ ) on the unstretched and uniaxially stretched PCL films were cultured in a D10 medium for four days. (a) Confocal microscopy images of fluorescein diacetate-stained live MSCs (double-headed arrow: ridge direction). (b) Quantitative analyses of the alignment and elongation efficiencies of MSCs represented by the normalized cell number in $\pm 10^{\circ}$ and long-to-short elliptic axis index, respectively $(n=3 ; * * *, p<0.001 ; * *, p<0.01 ; *, p<0.05 ; N S, p>0.05)$.

During the cell-substrate interaction, ridge depth is crucial for determining to what degree the cells can recognize given lateral dimensions. ${ }^{40}$ In agreement with this, we observed that MSCs achieved effective alignment on $\mathrm{UX}_{\mathrm{SC}}-\mathrm{PCL}$ and $\mathrm{UX}_{\mathrm{HP}}-\mathrm{PCL}$ but failed to align on $\mathrm{UX}_{\mathrm{CS}^{-}} \mathrm{PCL}$. Comparatively, although $\mathrm{UX}_{\mathrm{CS}^{-}}$ PCL had an inter-ridge distance similar to that of $\mathrm{UX}_{\mathrm{HP}}-\mathrm{PCL}$, it revealed a significantly lower ridge depth than that of $\mathrm{UX}_{\mathrm{HP}}-\mathrm{PCL}$ and $\mathrm{UX}_{\mathrm{SC}}-\mathrm{PCL}$, indicating that a threshold of ridge depth (e.g. $\sim 116 \mathrm{~nm}$ of $\mathrm{UX}_{\mathrm{CS}}$-PCL) might exist for the aligned MSCs on PCL films. In addition to ridge depth, inter-ridge distance could also affect MSC alignment on PCL films. Although $\mathrm{UX}_{\mathrm{SC}}-\mathrm{PCL}$ possessed deeper ridges/grooves than $\mathrm{UX}_{\mathrm{HP}}-\mathrm{PCL}$, it led to a lower efficiency of cell alignment, suggesting that a wider interridge distance (e.g. $>50 \mu \mathrm{m}$ of $\mathrm{UX}_{\mathrm{SC}}-\mathrm{PCL}$ ) could hinder substrates in eliciting cellular alignment. ${ }^{33,34}$ These observations would facilitate the understanding on how uniaxially stretched PCL films were able to modulate MSC alignment, and in this study, $\mathrm{UX}_{\mathrm{HP}^{-}}-\mathrm{PCL}$ was thus selected as a candidate for further investigation towards the construction of functionalized vascular TE scaffolds.

\subsection{Flexible PCL film micropatterns to upregulate MSCs differentiation}

Additional in-depth influences of $\mathrm{UX}_{\mathrm{HP}}$-PCL have been linked to MSCs myogenic differentiation towards vascular TE applications. Fig. 5a shows qRT-PCR analysis of SMCs contractile gene markers' expressions in MSCs, which revealed upregulated levels of ACTA2 $(2.7 \times$ increase, $p<0.001)$, CNN1 $(3.8 \times$ increase, $p<0.001)$ and MYH11 $(2.4 \times$ increase, $p=0.15)$ for the cells cultured on $\mathrm{UX}_{\mathrm{HP}}$-PCL for five days compared with those of the HP-PCL groups. These observations demonstrated the altered genetic expression of MSCs on $\mathrm{UX}_{\mathrm{HP}}$-PCL. It has been known that, in healthy arteries, SMCs possess the highly aligned organization with elongated shapes, whereas during in vitro culture transform into synthetic phenotypes with good spread and random organization. ${ }^{\mathbf{8}, 30}$ Such transition was similar to the observed changes of cell morphology and genetic expression for MSCs cultured on $\mathrm{UX}_{\mathrm{HP}}$-PCL and HP-PCL.

With protein detection, CLSM images of immunocytochemistry-labeled MSCs revealed positive expressions of SMCs contractile markers: SM- $\alpha$-actin, calponin and SM-MHC on both $\mathrm{UX}_{\mathrm{HP}}$-PCL and HP-PCL films (Fig. 5b-d). In contrast, no cellular fluorescence was observed for the corresponding negative control with no indication that nonspecific immune conjunction occurred. In the same manner, FACS quantitative analysis confirmed the positive expression of SMCs contractile markers for MSCs on $\mathrm{UX}_{\mathrm{HP}}$-PCL and HP-PCL (positive cell number of each marker: $<0.5 \%$ for Neg Ctrl $v s$. $>30 \%$ for PCL film groups, $p$ $<0.001$; Fig. 6a-c). When comparing $\mathrm{UX}_{\mathrm{HP}}-\mathrm{PCL}$ and HP-PCL groups, CLSM images show that the staining of SM- $\alpha$-actin, calponin and SM-MHC was higher in the $\mathrm{UX}_{\mathrm{HP}}-\mathrm{PCL}$ groups with higher levels of SM- $\alpha$-actin expressed than late-term myogenic differentiation protein markers such as SM-MHC (Fig. 5b-d). MSCs cultured on $\mathrm{UX}_{\mathrm{HP}}$-PCL obtained significant increase in positive cell numbers ( $v s$. HP-PCL: $9.8 \%$ higher for SM- $\alpha$-actin, $7.9 \%$ higher for calponin, and 11.3\% higher for SM-MHC, $p<$ 0.001; Fig. 6a-c) and average cell expression intensity (vs. HPPCL: $23.5 \%$ higher for SM- $\alpha$-actin, $p<0.001 ; 24.3 \%$ higher for 
(a)

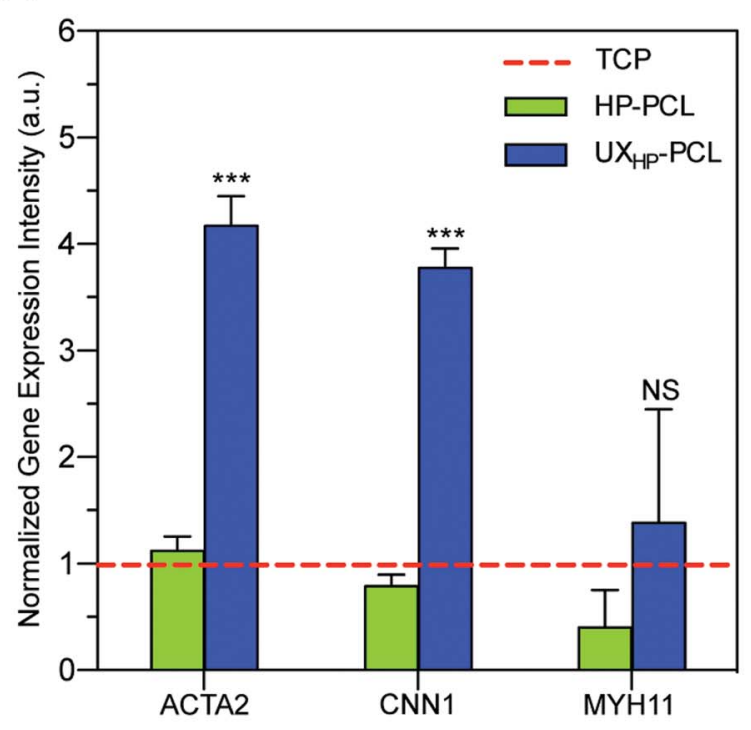

(b) DNA

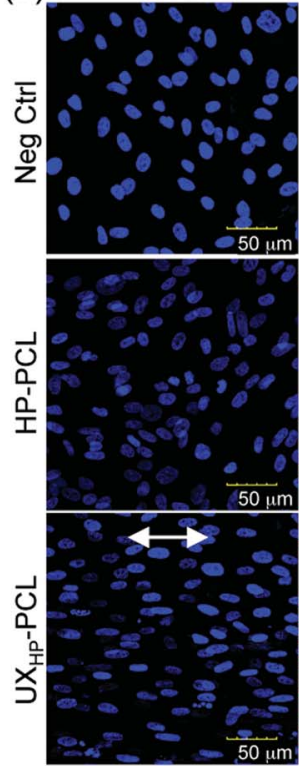

SM- $\alpha-$ actin

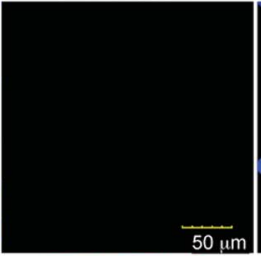
Merged
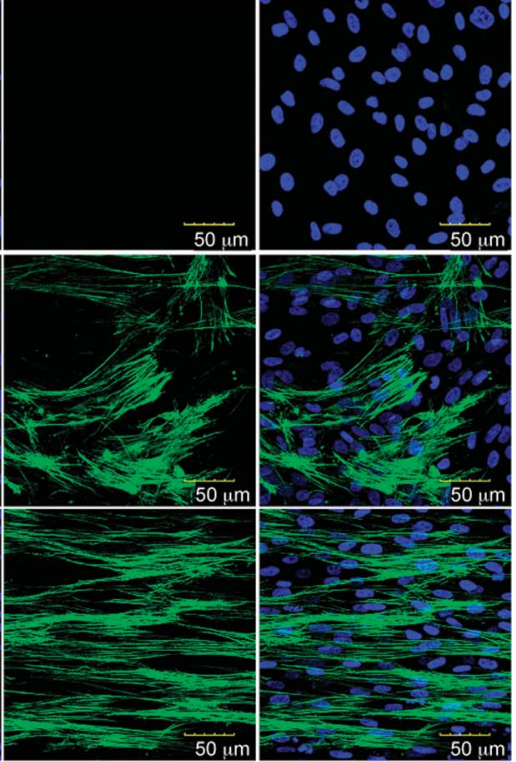

(c) Calponin Merged

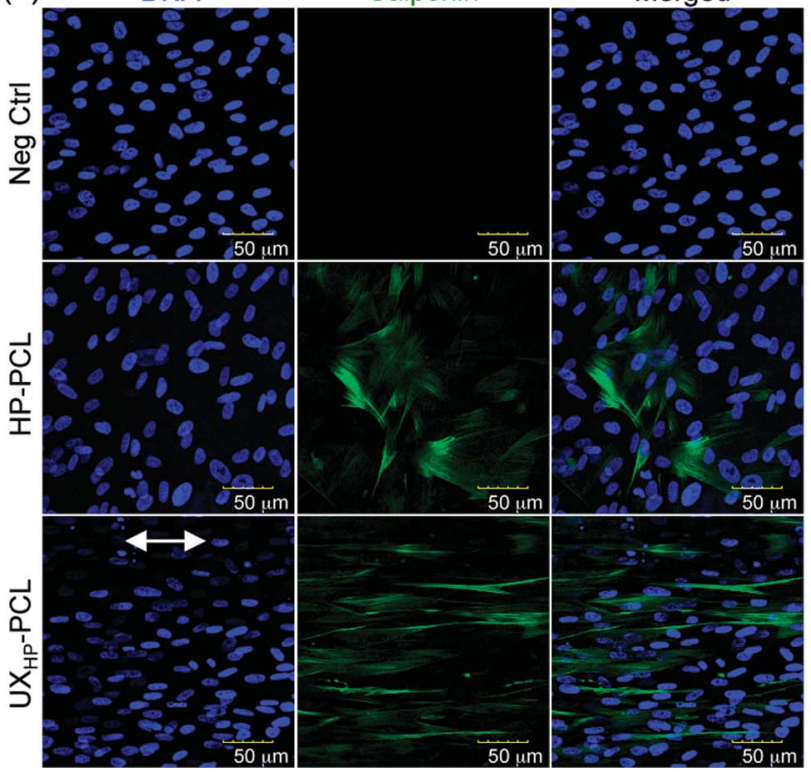

SM-MHC

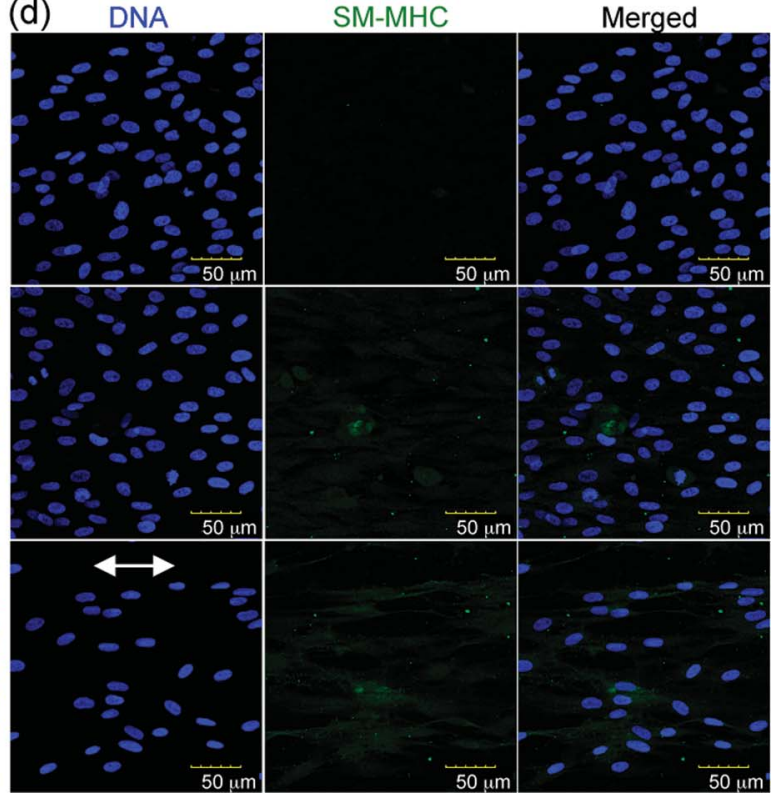

Fig. 5 Modulation of MSCs to express smooth muscle differentiation markers. Cells (passage $6,5 \mathrm{k} \mathrm{cm}^{-2}$ ) on $\mathrm{HP}-\mathrm{PCL}$ and $U X_{H P}-\mathrm{PCL}$ were

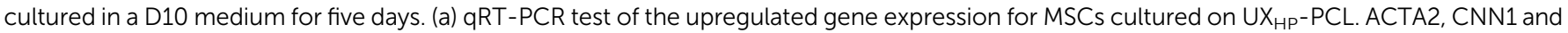
MYH11 representing the genetic markers related to early-, middle- and late-term smooth muscle differentiation, respectively (TCP: tissue culture plate; $n=3$; vs. HP-PCL groups: ***, $p<0.001 ; \mathrm{NS}, p=0.15)$. (b-d) Confocal microscopy images of the expression and organization of smooth muscle stress filaments using immunocytochemistry straining. SM- $\alpha$-actin, calponin and SM-MHC representing the protein markers related to early-, middle- and late-term smooth muscle differentiation, respectively (Neg Ctrl: negative control of the IgG isotypes; green color: investigated markers; blue color: nucleus DNA; double-headed arrow: ridge direction).

calponin, $p<0.05$; and 17.1\% higher for SM-MHC, $p<0.001$; Fig. 6d-f).

Our results through qRT-PCR and the immunocytochemistry analyses using CLSM and FACS demonstrated that $\mathrm{UX}_{\mathrm{HP}}-\mathrm{PCL}$ upregulated the expression of SM- $\alpha$-actin, calponin and SMMHC in MSCs at both the gene and protein levels. These markers associated with SMCs, and they are expressed in early, middle and late SM differentiation. ${ }^{8}$ Moreover, CLSM images of MSCs on $\mathrm{UX}_{\mathrm{HP}}-\mathrm{PCL}$ revealed the aligned organization of SM contraction-related filaments in a controlled direction along the ridges (Fig. 5b-d), whereas randomly organized filaments were observed for the cells on HP-PCL. Such induced filament alignment on $\mathrm{UX}_{\mathrm{HP}}-\mathrm{PCL}$ might also facilitate the contractile SMC-like phenotype of the MSCs, as a recent study on cardiomyocytes indicated that contraction behavior relied on both the positive expression and ordered organization of cellular stress filaments. ${ }^{32}$ Thus, $\mathrm{UX}_{\mathrm{HP}}$-PCL could be used to promote MSCs as potential cell sources for vascular TE applications. 


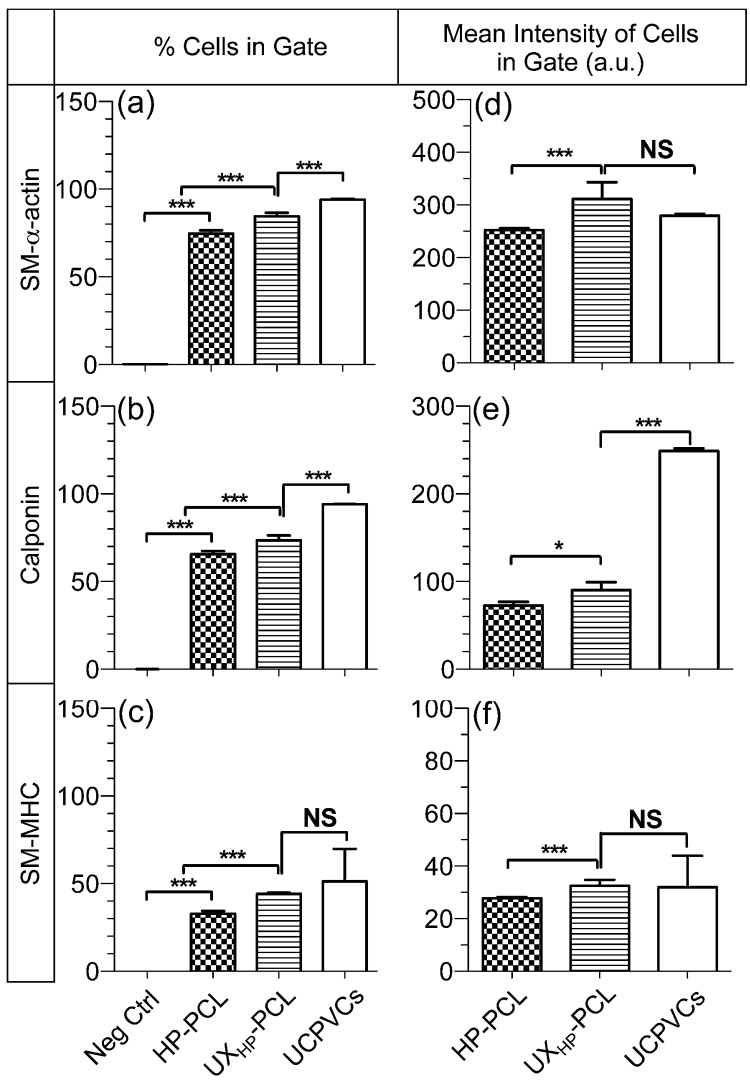

Fig. 6 Increased positive cell numbers and expression intensities for MSCs cultured on UX $\mathrm{HP}_{\mathrm{HP}}-\mathrm{PCL}$. MSCs (passage $6,5 \mathrm{k} \mathrm{cm}^{-2}$ ) on $\mathrm{HP}-\mathrm{PCL}$ and $U X_{H P}-P C L$ and UCPVCs (passage $2,5 \mathrm{k} \mathrm{cm}^{-2}$ ) on TCP were cultured in a D10 medium for five days, and analyzed using flow cytometry (10 000 cells) through immunocytochemistry labeling. (ac) $\%$ cells in gate. (d-e) Mean intensity of cells in gate. SM- $\alpha$-actin, calponin and $\mathrm{SM}-\mathrm{MHC}$ representing the protein markers related to early-, middle- and late-term smooth muscle differentiation, respectively (Neg Ctrl: negative control of the IgG-isotypes; UCPVCs: positive control; $n=3$; ***, $p<0.001 ; * *, p<0.01 ; *, p<0.05$; NS, $p>0.05$ ).

Despite the enhanced response of MSCs on $\mathrm{UX}_{\mathrm{HP}}-\mathrm{PCL}$, it should be noted that these MSCs, as compared to Pos Ctrl, still exhibited a lower expression of SMCs markers at the positive cell number ( $v$ s. UCPVCs: $0.9 \times$ for SM- $\alpha$-actin, $p<0.001 ; 0.8 \times$ for calponin, $p<0.01$; and $0.9 \times$ for SM-MHC, $p=0.54$; Fig. $6 \mathrm{a}-$ c), although their average cell expression intensity for SM- $\alpha$ actin and SM-MHC was comparable ( $p>0.05$; Fig. $6 \mathrm{~d}$ and f).

To understand the reasons behind the observed MSCs differentiation, we investigated the alterations of subcellular organelles on $\mathrm{UX}_{\mathrm{HP}}-\mathrm{PCL}$. Through cytoskeletal F-actin and nucleus DNA labeling, Fig. 7a shows the CLSM images of MSCs on $\mathrm{UX}_{\mathrm{HP}}-\mathrm{PCL}$ with typically spindle-like morphologies, reduced spreading and ordered cytoskeleton fibers, which have been known to associate with SMCs in differentiated status. ${ }^{8,30,31}$ In contrast, MSCs spread well with random cytoskeletal filaments on HP-PCL. Correspondingly, MSCs nuclei on $\mathrm{UX}_{\mathrm{HP}}-\mathrm{PCL}$ deformed into a more elongated morphology along the ridges with increased alignment efficiency $(2.5 \times$ higher, $p<0.001$; Fig. $7 \mathrm{a}$ and $\mathrm{b})$ and reduced CNSI $(0.3 \times$ lower, $p<0.001)$ as compared to those of the HP-PCL groups, respectively.
Geometric structures to trigger cell differentiation have been known via mechanotransduction pathways, ${ }^{32,41}$ during which cells recognized the substrate geometrices with altered focal adhesion distribution, migration and extension to align into elongated shapes. Such elongation of cell shape during direct mechanotransduction could result in aligned cytoskeletonal fibers triggering nucleus deformation, leading to structural adjustment of the DNA and nucleus pores, changed accessibility of transcriptional factors, and final alterations in gene expression. ${ }^{41-43}$ In this study, MSCs cultured on $\mathrm{UX}_{\mathrm{HP}}-\mathrm{PCL}$ demonstrated altered cell morphology, cytoskeletonal reorientation and nucleus elongation, suggesting that the upregulation of SM- $\alpha$-actin, calponin and SM-MHC in MSCs could be, in part, attributed to the ridges/grooves of $\mathrm{UX}_{\mathrm{HP}}-\mathrm{PCL}$ via direct mechanotransduction. Such a differentiation effect of geometric cues on MSCs has not been reported, which agreed with the previous observations on SMCs, including marker expressions of SM- $\alpha$-actin, ${ }^{6}$ calponin, ${ }^{6}$ smoothelin $^{6}$ and SMMHC. ${ }^{6,8}$ In addition to topographical geometries, $\mathrm{UX}_{\mathrm{HP}}-\mathrm{PCL}$, compared to HP-PCL, had a higher Young's Modulus, which might also have accounted for the elevated SMCs marker expression for MSCs cultured on $\mathrm{UX}_{\mathrm{HP}}-\mathrm{PCL}$ as recent evidence showed that the stiffer substrate could result in MSCs with the up-regulated expression of SM- $\alpha$-actin and calponin- $1 .^{31}$

On the other hand, the source of stem cells might influence the selectivity of gene expression on geometric cues. Bone marrow-divided stem cells (e.g. human fetal bone MSCs) with cultures in non-differentiating medium have been reported to differentiate towards myocardial lineages on anisotropic fibers $^{44,45}$ and ridges/grooves, ${ }^{15,34,43}$ whereas human embryonic stem cells on both patterned nanoscale ridges/grooves ${ }^{46}$ and aligned electrospun fibers ${ }^{47}$ tended to enhance the differentiation towards neurons. However, these studies lacked investigation on the SMCs contractile markers, although MSCs have shown promise for vascular TE application. ${ }^{17,18}$ Herein, we demonstrated that the ridges/grooves of $\mathrm{UX}_{\mathrm{HP}}-\mathrm{PCL}$ could induce improved gene and protein expressions of SM- $\alpha$-actin, calponin and SM-MHC in MSCs. Thus, this confirms the ability of geometric cues in modulating MSCs differentiation along myogenic lineage. ${ }^{15,34,43-45}$

\subsection{Construction of functionalized $3 D$ tubular scaffolds with double-surface micropatterns}

We finally applied $\mathrm{UX}_{\mathrm{HP}}$-PCL to construct $3 \mathrm{D}$ tubular vascular TE scaffold $(\sim 2.3 \mathrm{~mm}$ in diameter; Fig. $8 \mathrm{a}$ and b) through the rolling of the film around a rod, and then attaching it through heat welding. SEM images of the inner and outer scaffold surfaces revealed similar circumferential anisotropy of ridges/ grooves in a direction perpendicular to the tube (Fig. 8b). Seeding MSCs on both surfaces of the opened $\mathrm{UX}_{\mathrm{HP}}$-PCL-based scaffold, an engineered hybrid vascular wall construction comprising of layered MSCs/PCL/MSCs was achieved with anisotropic organization along the ridges (Fig. 8c). Previously, different strategies, such as mechanical stimuli ${ }^{17}$ and biochemical factors, ${ }^{18}$ have been studied for functionalized generation of vascular grafts. However, in this study, we 

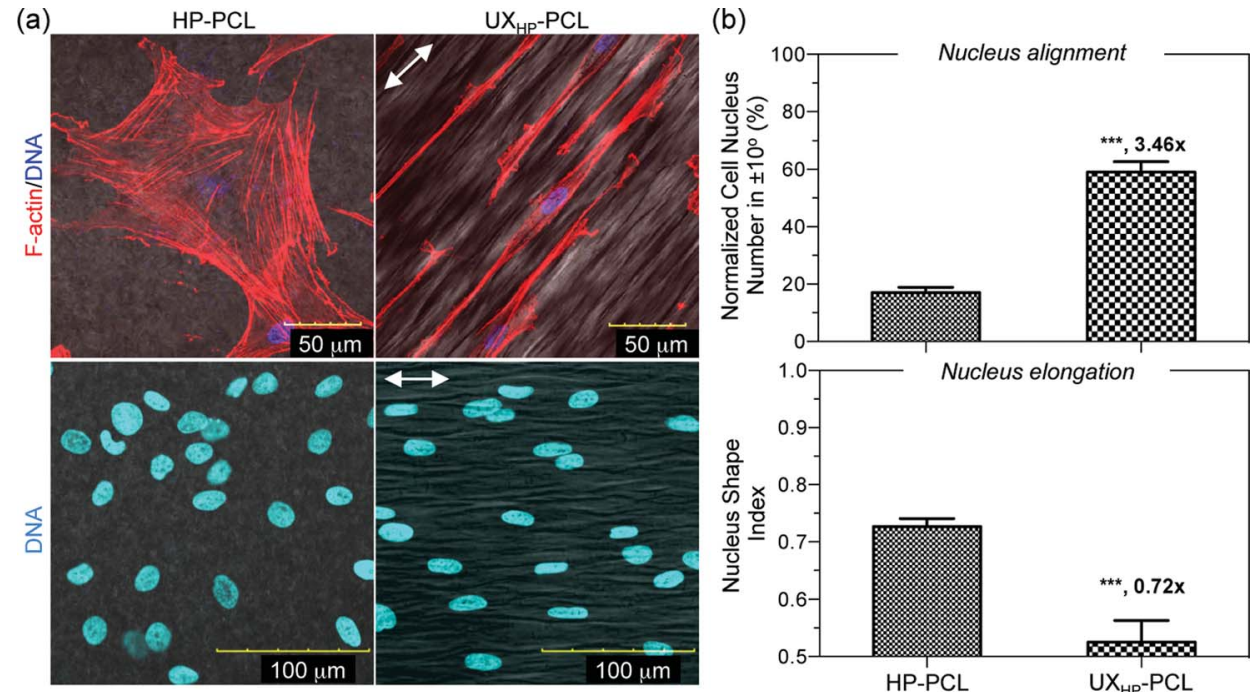

Fig. 7 Subcellular organelle alterations of MSCs on UX $\mathrm{HP}_{\mathrm{P}}-\mathrm{PCL}$. Cells (passage $6,5 \mathrm{k} \mathrm{cm}^{-2}$ ) on HP-PCL and UX $\mathrm{HP}_{\mathrm{HP}}-\mathrm{PCL}$ were cultured in D10 medium for five days. (a) Confocal microscopy images of the MSCs reorganized cytoskeleton and deformed nuclei on UX $\mathrm{X}_{\mathrm{HP}}-\mathrm{PCL}$ (red color: cytoskeletal F-actin; blue color: nucleus DNA; double-headed arrow: ridge direction). (b) Quantitative analyses of the nucleus alignment and elongation efficiencies represented by the normalized nucleus number in $\pm 10^{\circ}$ and nucleus shape index, respectively $(n=3 ; * * *, p<0.001)$.
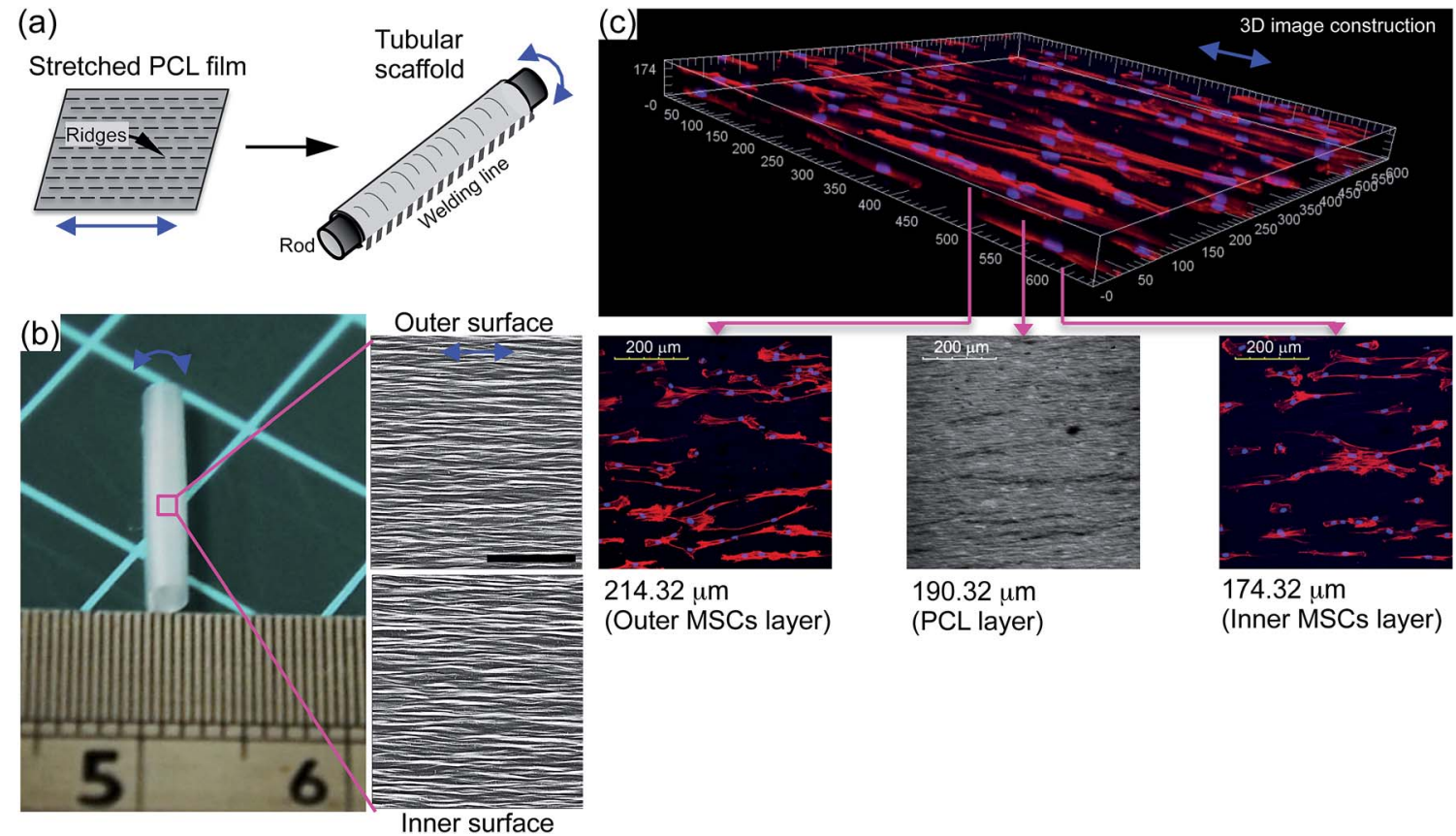

Fig. 8 (a) Schematic illustration of 3D tubular vascular TE scaffold construction (double-headed arrow: ridge direction). (b) Small-diameter scaffold fabricated from UX $\mathrm{HP}_{\mathrm{HP}}-\mathrm{PCL}$ and SEM images of the outer- and inner-wall morphologies (scale bar $=100 \mu \mathrm{m}$ ). (c) Confocal microscopy images of a hybrid vascular wall construction comprised of layered MSCs/PCL/MSCs with aligned architecture similar to that of tunica media. Cells (passage $6,5 \mathrm{k} \mathrm{cm}^{-2}$ ) were seeded on both surfaces of the opened scaffold and cultured in a D10 medium for five days (red color: F-actin; blue color: DNA; double-headed arrow: ridge direction).

developed flexible film micropatterns of $\mathrm{UX}_{\mathrm{HP}}-\mathrm{PCL}$. Vascular TE scaffolds with incorporation of these geometric cues could regenerate the ordered architecture of tunica media with aligned MSC layers and regulate MSCs towards contractile SMCs-like phenotypes in a more controllable and cost effective way, as well as avoiding the introduction of side effects such as atherosclerosis from biochemical cues. ${ }^{23,46}$ Benefiting from uniaxial thermal stretching, $\mathrm{UX}_{\mathrm{HP}}-\mathrm{PCL}$ achieved improved mechanical performance without sacrificing the film's elasticity, which ensured the safety considerations for engineered vascular TE scaffolds and provided them the unique tubular patency to facilitate operative storability and simplicity of 
surgical handling when the scaffolds were in contact with biological liquids (Fig. S1 $\dagger$ ). ${ }^{2,4}$ Furthermore, our previous study demonstrated that the micropatterns of $\mathrm{UX}_{\mathrm{HP}}-\mathrm{PCL}$ had enhanced stability against erosive environments; ${ }^{26}$ thus, they could provide long-term cell regulation for the engineered vascular TE scaffolds even after implantation in vivo. In short, the $\mathrm{UX}_{\mathrm{HP}}$-PCL-based vascular $\mathrm{TE}$ scaffold possessed unique mechano- and bio-functions. Moreover, with the incorporation of MSCs, it has the potential to be used for generating engineered, autologous, and commercially available vascular grafts with the desired tunica media architecture of native vessels.

\section{Conclusions}

Herein, we presented the development of flexible film micropatterns for the functionalized construction of vascular TE scaffolds. PCL films after uniaxial stretching resulted in topographical micropatterns comprised of ridges/grooves, and mechanical enhancement in terms of yield stress, Young's Modulus and fracture stress without sacrificing the film's elasticity. Culturing on such PCL film micropatterns, MSCs selfaligned along the ridges into more elongated morphology as compared to that of the unstretched film groups. MSCs obtained a contractile SMC-like phenotype with upregulation and ordered organization of SM- $\alpha$-actin, calponin, and SMMHC filaments. The PCL film micropatterns could be rolled into a small-diameter 3D tubular scaffold with circumferential anisotropy of ridges/grooves and for the incorporation of MSCs, which facilitated a hybrid sandwich-like wall construction with ordered cell architecture, similar to that of the tunica media. These results provide insight into how geometric cues are able to regulate stem cells with desired functions and have significant implications for designing functionalized vascular TE scaffolds with appropriate topographical geometries for guiding tunica media regeneration with microscale control of cell alignment and genetic expression.

\section{Acknowledgements}

The authors thank Dr Li Tao and Mr Sandikin Dedy from the National University of Singapore for their assistance in the AFM characterization and MSCs isolation in this project, respectively. This work was supported by a grant from the Ministry of Education, Singapore (R 265-000-300-112). Dr Zu-yong Wang would like to thank the National University of Singapore for awarding him the research scholarship. Dr Jerry Chan received salary support from the Ministry of Health's (Singapore) NMRC Clinician-Scientist Award (NMRC/CSA/043/2012).

\section{References}

1 C. Arrigoni, D. Camozzi and A. Remuzzi, Cell Transplant., 2006, 15, S119-S125.

2 J. Chlupac, E. Filova and L. Bacakova, Physiol. Res., 2009, 58(suppl 2), S119-S139.

3 W. J. Zhang, W. Liu, L. Cui and Y. L. Cao, J. Cell. Mol. Med., 2007, 11, 945-957.
4 S. Sarkar, T. Schmitz-Rixen, G. Hamilton and A. M. Seifalian, Med. Biol. Eng. Comput., 2007, 45, 327-336.

5 J. A. Hu, X. A. Sun, H. Y. Ma, C. Q. Xie, Y. E. Chen and P. X. Ma, Biomaterials, 2010, 31, 7971-7977.

6 Y. Cao, Y. F. Poon, J. Feng, S. Rayatpisheh, V. Chan and M. B. Chan-Park, Biomaterials, 2010, 31, 6228-6238.

7 R. G. Thakar, F. Ho, N. F. Huang, D. Liepmann and S. Li, Biochem. Biophys. Res. Commun., 2003, 307, 883-890.

8 C. Williams, X. Q. Brown, E. Bartolak-Suki, H. W. Ma, A. Chilkoti and J. Y. Wong, Biomaterials, 2011, 32, 410418.

9 P. T. Ohara and R. C. Buck, Exp. Cell Res., 1979, 121, 235-249.

10 S. Fujita, M. Ohshima and H. Iwata, J. R. Soc., Interface, 2009, 6, S269-S277.

11 R. G. Thakar, Q. Cheng, S. Patel, J. Chu, M. Nasir, D. Liepmann, K. Komvopoulos and S. Li, Biophys. J., 2009, 96, 3423-3432.

12 P. Zorlutuna, P. Vadgama and V. Hasirci, J. Tissue Eng. Regener. Med., 2010, 4, 628-637.

13 S. J. Liliensiek, J. A. Wood, J. Yong, R. Auerbach, P. F. Nealey and C. J. Murphy, Biomaterials, 2010, 31, 5418-5426.

14 W. Y. Yeong, H. Y. Yu, K. P. Lim, K. L. G. Ng, Y. C. F. Boey, V. S. Subbu and L. P. Tan, Tissue Eng., Part C, 2010, 16, 1011-1021.

15 Z. Y. Wang, E. Y. Teo, M. S. Chong, Q. Y. Zhang, J. Lim, Z. Y. Zhang, M. H. Hong, E. S. Thian, J. K. Chan and S. H. Teoh, Tissue Eng., Part C, 2013, 19, 538-549.

16 M. B. Chan-Park, J. Y. Shen, Y. Cao, Y. Xiong, Y. X. Liu, S. Rayatpisheh, G. C. W. Kang and H. P. Greisler, J. Biomed. Mater. Res., Part A, 2009, 91A, 629-634.

17 N. F. Huang and S. Li, Regener. Med., 2008, 3, 877-892.

18 Z. D. Gong and L. E. Niklason, FASEB J., 2008, 22, 1635-1648.

19 C. Wang, S. Yin, L. Cen, Q. H. Liu, W. Liu, Y. L. Cao and L. Cui, Tissue Eng., Part A, 2010, 16, 1201-1213.

20 S. Kern, H. Eichler, J. Stoeve, H. Klüter and K. Bieback, Stem cells, 2006, 24, 1294-1301.

21 C. K. Hashi, Y. Q. Zhu, G. Y. Yang, W. L. Young, B. S. Hsiao, K. Wang, B. Chu and S. Li, Proc. Natl. Acad. Sci. U. S. A., 2007, 104, 11915-11920.

22 K. Le Blanc, C. Tammik, K. Rosendahl, E. Zetterberg and O. Ringden, Exp. Hematol., 2003, 31, 890-896.

23 Y. Narita, A. Yamawaki, H. Kagami, M. Ueda and Y. Ueda, Cell Tissue Res., 2008, 333, 449-459.

24 K. S. Tiaw, S. H. Teoh, R. Chen and M. H. Hong, Biomacromolecules, 2007, 8, 807-816.

25 Z. Y. Wang, J. Lim, Q. Y. Zhang, E. Y. Teo, F. Wen, J. Chan, S. H. Teoh and M. H. Hong, Defense Science Research Conference and Expo, IEEE, 2011, pp. 1-5.

26 Z. Y. Wang, J. Lim, Y. S. Ho, Q. Y. Zhang, M. S. Chong, M. Tang, M. H. Hong, J. K. Chan, S. H. Teoh and E. S. Thian, J. Biomed. Mater. Res., Part A, 2014, 102, 21972207.

27 G. Konig, T. N. McAllister, N. Dusserre, S. A. Garrido, C. Iyican, A. Marini, A. Fiorillo, H. Avila, W. Wystrychowski, K. Zagalski, M. Maruszewski, A. L. Jones, L. Cierpka, L. M. de la Fuente and N. L'Heureux, Biomaterials, 2009, 30, 1542-1550. 
28 Z. Y. Zhang, S. H. Teoh, J. H. Hui, N. M. Fisk, M. Choolani and J. K. Chan, Biomaterials, 2012, 33, 2656-2672.

29 Z. Y. Zhang, S. H. Teoh, M. S. Chong, J. T. Schantz, N. M. Fisk, M. A. Choolani and J. Chan, Stem Cells, 2009, 27, 126-137.

30 J. A. Beamish, P. He, K. Kottke-Marchant and R. E. Marchant, Tissue Eng., Part B, 2010, 16, 467-491.

31 J. S. Park, J. S. Chu, A. D. Tsou, R. Diop, Z. Y. Tang, A. J. Wang and S. Li, Biomaterials, 2011, 32, 3921-3930.

32 P. Y. Wang, J. Yu, J. H. Lin and W. B. Tsai, Acta Biomater., 2011, 7, 3285-3293.

33 H. Aubin, J. W. Nichol, C. B. Hutson, H. Bae, A. L. Sieminski, D. M. Cropek, P. Akhyari and A. Khademhosseini, Biomaterials, 2010, 31, 6941-6951.

34 H. Q. Li, F. Wen, Y. S. Wong, F. Y. C. Boey, V. S. Subbu, D. T. Leong, K. W. Ng, G. K. L. Ng and L. P. Tan, Acta Biomater., 2012, 8, 531-539.

35 J. Greener, A. Tsou and T. Blanton, Polym. Eng. Sci., 1999, 39, 2403-2418.

36 V. Miri, S. Elkoun, F. Peurton, C. Vanmansart, J.-M. Lefebvre, P. Krawczak and R. Seguela, Macromolecules, 2008, 41, 92349244.

37 S. Jana and M. Zhang, J. Mater. Chem. B, 2013, 1, 25752581.
38 S. Sarkar, G. Y. Lee, J. Y. Wong and T. A. Desai, Biomaterials, 2006, 27, 4775-4782.

39 R. J. Manson, J. M. Unger, A. Ali, S. M. Gage and J. H. Lawson, Semin. Nephrol., 2012, 32, 582-591.

40 J. Y. Lim and H. J. Donahue, Tissue Eng., 2007, 13, 18791891.

41 L. E. McNamara, R. J. McMurray, M. J. Biggs, F. Kantawong, R. O. Oreffo and M. J. Dalby, J. Tissue Eng., 2010, 2010, 120623.

42 N. Wang, J. D. Tytell and D. E. Ingber, Nat. Rev. Mol. Cell Biol., 2009, 10, 75-82.

43 C. Y. Tay, H. Yu, M. Pal, W. S. Leong, N. S. Tan, K. W. Ng, D. T. Leong and L. P. Tan, Exp. Cell Res., 2010, 316, 11591168.

$44 \mathrm{H} . \mathrm{Li}, \mathrm{Y} . \mathrm{S}$. Wong, F. Wen, K. W. Ng, G. K. Ng, S. S. Venkatraman, F. Y. Boey and L. P. Tan, Macromol. Biosci., 2013, 13, 299-310.

45 J. M. Dang and K. W. Leong, Adv. Mater., 2007, 19, 27752779.

46 M. R. Lee, K. W. Kwon, H. Jung, H. N. Kim, K. Y. Suh, K. Kim and K. S. Kim, Biomaterials, 2010, 31, 4360-4366.

47 J. W. Xie, S. M. Willerth, X. R. Li, M. R. Macewan, A. Rader, S. E. Sakiyama-Elbert and Y. N. Xia, Biomaterials, 2009, 30, 354-362. 